\title{
Monetary Policy Rules in Transition Economies: The Impact of
}

\author{
Ambiguity $^{1}$
}

\author{
by \\ Subrata Ghatak ${ }^{2}$ and Willy Spanjers ${ }^{3}$ \\ $20^{\text {th }}$ February 2007
}

\begin{abstract}
This paper discusses the potential benefits of monetary policy rules for transition economies [TEs]. It is argued that the nominal interest rate may fail to be the appropriate instrument in such rules. One reason is the amount of non-calculable political and economic risk inherent in TEs. These risks lead to a significant and volatile ambiguity premium in the interest rate over and above the normal risk premium, which makes the real equilibrium interest rate difficult to measure. Therefore, a monetary aggregate like the money base may be more appropriate as the instrument for monetary policy rules in TEs.

Keywords: Monetary Policy, Transition Economies, Political Risk, Ambiguity.

JEL Classification: E5, E52.

\footnotetext{
${ }^{1}$ The authors are grateful for the comments of the participants at the 2006 INFER Workshop on Monetary Economics at Kingston University, UK.

${ }^{2}$ Prof. Subrata Ghatak, School of Economics, Kingston University, Penrhyn Road, Kingston-uponThames, Surrey KT1 2EE, United Kingdom. Email: subrataghatak@aol.com.

${ }^{3}$ Dr. Willy Spanjers, School of Economics, Kingston University, Penrhyn Road, Kingston-upon-Thames, Surrey KT1 2EE, United Kingdom. Email: w.spanjers@kingston.ac.uk.
} 


\section{Introduction}

The use of monetary policy rules to evaluate and describe central bank policy actions has been growing rapidly. Much of the research on policy rules has focused on economies with highly developed asset markets, especially markets for debt and foreign exchange.

The main type of monetary policy rule suggested in the early 1990s was the Taylor rule, which was originally designed for the USA, but also worked well in other developed economies. The main research tool used to design that rule was a model of seven large economies. Each economy was assumed to have both a fully developed long term bond market and a foreign exchange market with a high degree of capital mobility.

The Taylor rule is defined by

$$
r=r^{*}+\beta\left(\pi-\pi^{*}\right)+\gamma\left(Y-Y^{*}\right)
$$

where

$r \quad$ denotes the actual nominal short term interest rate

$r^{*} \quad$ denotes the equilibrium nominal short term interest rate

$\pi \quad$ denotes the actual rate of inflation

$\pi^{*} \quad$ denotes the equilibrium rate of inflation

$Y \quad$ denotes the actual output and 
$Y^{*} \quad$ denotes the capacity output.

A question that arises is if the Taylor rule is also a useful guide for monetary policy in transition economies. It should be noted that the Taylor rule does not take direct account of shocks, which one would expect to occur more prominently in transition economies than in developed economies. Still, Taylor rules have many of the same advantages in transition economies as they have in developed countries. In particular, for transition economies that do not choose a policy of a "permanently” fixed exchange rate (perhaps through a currency board or through a common currency, i.e. dollarization), a sound monetary policy should be based on the trinity of a flexible exchange rate, an inflation target, and a monetary policy rule. But it will be necessary to change some of the features of the typical kind of policy rule that is recommended for countries with more developed financial markets.

In particular, when considering monetary policy rules for transition economies, the following major issues arise:

1. Which instruments should be included in the monetary policy rule?

2. What specific rule should be followed?

3. What is the role of the exchange rate in a monetary policy rule?

4. What is the role of uncertainty and ambiguity? 


\section{Monetary Policy Rules}

Before addressing these issues in more detail, we state what precisely we mean by a monetary policy rule. In the context of our analysis, a monetary policy rule is understood to be a contingency plan that specifies clearly the cases under which a central bank should change the instruments of monetary policy. E.g. the Taylor rule describes the change in the instruments that would accompany an increase in inflation or in real GDP relative to potential GDP. To be credible, a policy rule should be used for many periods in the future.

In research on policy rules, the instrument has been a short term overnight interest rate. But other instruments in a policy rule could be the money base, or some other monetary aggregate. In his seminal paper Taylor (1979), for instance, uses the money supply as the instrument. McCallum (1988) sees advantages of policy rules with a monetary aggregate as the instrument and the famous Friedman growth rate rule also has a monetary aggregate as the instrument. Since the mid 1980s, however, it was found that the interest rate is a more practical instrument in policy rules.

Thus, one may want to consider a modified Taylor rule to take these considerations into account. A central bank may want to implement a general interest rate rule in order to achieve specific policy objectives. Such rule may take the following form: 


$$
r_{t}=r^{*}+\alpha r_{t-1}+\beta\left(\pi_{t}-\pi^{*}\right)+\gamma\left(Y-Y^{*}\right)+\delta\left(e_{t}-e_{t-1}\right)+\varepsilon_{m t}
$$

where $t$ is the time index, $e_{t}$ denotes the exchange rate and $\varepsilon_{m t}$ denotes a domestic monetary policy shock.

More generally, one may want to consider three special cases of monetary policy rules. They are rules that operate at the moment of monetary policy shocks and, therefore, are feedback rules for monetary policy. In particular, we mention the inflation targeting rule, the Taylor rule and the managed exchange rate rule. These rules are considered in the context of a central bank that is engaged in interest rate smoothing, but of course, a similar approach can be applied for the smoothing of other instruments as, e.g. the exchange rate.

The inflation targeting rule is

$$
r_{t}=\rho_{r} r_{t-1}+\left(1-\rho_{r}\right) \beta\left(\pi_{t}-\pi^{*}\right)+\varepsilon_{m t}
$$

where $\rho_{r}$ is the interest rate smoothing parameter.

The Taylor rule extends the inflation targeting rule by adding the deviation of output from its capacity:

$$
r_{t}=\rho_{r} r_{t-1}+\left(1-\rho_{r}\right) \beta\left(\pi_{t}-\pi^{*}\right)+\left(1-\rho_{r}\right) \gamma\left(Y_{t}-Y^{*}\right)+\varepsilon_{m t}
$$


The managed exchange rate rule, finally, is obtained by adding a reaction to the devaluation of the exchange rate, as exchange rate volatility is a cause for worry to many countries. The rule is

$$
r_{t}=\rho_{r} r_{t-1}+\left(1-\rho_{r}\right) \beta\left(\pi_{t}-\pi^{*}\right)+\left(1-\rho_{r}\right) \gamma\left(Y-Y^{*}\right)+\left(1-\rho_{r}\right) \delta\left(e_{t}-e_{t-1}\right)+\varepsilon_{m t}
$$

The actual short term interest rate as set by the central bank may, however, at times deviate from the one indicated by the appropriate policy rule, as some special factors of the policy environment cannot be included in the rule. Liquidity crises in financial markets will usually require such discretion. The 1987 stock market crash in the USA is one such example. Before this crash, the Fed was increasing the short term interest rate, apparently because inflation and the output gap were increasing. But when liquidity became a concern after the crash, the Fed lowered the interest rate and thereby provided more liquidity. Such discretionary actions are, of course, relative to the benchmark rule, which in this example is the Taylor rule.

The size of the interest rate responses in policy rules matter greatly for economic performance. Changing the interest rate by more than one for one with inflation is a crucial property of a good monetary policy rule. A response that is smaller than one-toone can result in very poor performance. An example of this is the USA's response of the interest rate to inflation in the late 1960s and the 1970s in comparison with the 1980s and 1990s. 
Another important advantage of having a monetary policy rule is that it increases the transparency of monetary policy. Financial market analysts frequently use monetary policy rules to figure out what central banks are going to do. Whether the rule is good or bad, they use monetary policy rules to help predict the short term interest rate. Such a predication is also useful for analyzing exchange rates, bond prices, or stock prices.

The following consideration determines the choice between a policy rule with the interest rate as the instrument and a policy rule with the money base (or some other monetary aggregate) as the instrument. If there is too much uncertainty in measuring the real interest rate or if there are relatively big shocks to investment or net exports, then a monetary aggregate is the preferred instrument. The same is true if it is difficult to measure the equilibrium real interest rate. But if velocity shocks are big, then the interest rate is the more suited instrument.

The preference for the interest rate instrument in recent works on policy rules primarily reflects velocity uncertainty. But there are circumstances where real interest rate measurement is difficult and where the over night nominal interest rate is not the best guide. Such cases may very well be present in transition economies. In a situation of a high growth rate and/or a high inflation rate, the real interest rate is hard to measure and the risk premia can be high and variable, e.g. due to the presence of political uncertainty. With an interest rate rule, uncertainty about the equilibrium real interest rate translates into policy errors. Policy makers in transition economies might want to give greater 
consideration to policy rules with monetary aggregates, even if rules with the interest rate become the preferred choice.

Just because monetary policy rules can be written down as a mechanical-looking equation, this does not imply that central banks should follow them mechanically. To the contrary, most proposals for monetary policy rules suggest that the rules are best used as guidelines, or general policy frameworks. Discretion is needed to implement the policy rule.

The Taylor rule [Taylor (1993)] suggests a very specific policy for the central bank. It calls for the quarterly average US interest rate to rise by 1.5 times any increase in the four-quarter average inflation rate plus 0.5 times any increase in the output gap. Even so, the Taylor rule is a guideline for assessing interest rate decisions. Discretion is needed to assess monthly data on commodity prices, employment, industrial output and other variables, in order to estimate or predict the current quarterly inflation rate and the output gap.

\section{Inflation Targeting}

Having an inflation target is essential for good monetary policy making in cases where a country decides on a flexible exchange rate regime. The inflation target places the nominal anchor on domestic prices. In this it contrasts with a fixed exchange rate regime, a currency board, or dollarization. The increased focus on the inflation target in transition 
economies is a welcome development. By the target rate of inflation we mean the value level of inflation that one would like to be the one that the actual inflation rate fluctuates around. The following table provides an impression of the inflation targets of some countries that operate an inflation targeting regime

\begin{tabular}{|l|l|l|}
\hline Country & Inflation target & Target's horizon \\
\hline Australia & $2 \%$ to $3 \%$ (since 1993$)$ & Medium term \\
\hline Brazil & $5.1 \%$ (for 2005) & 1 year \\
\hline Canada & $1 \%$ to $3 \%$ (since 1998$)$ & Medium term \\
\hline Chile & $2 \%$ to $4 \%$ (since 2001$)$ & Medium term \\
\hline Colombia & $3.5 \%$ to $4.5 \%$ (for 2007$)$ & Medium term \\
\hline Czech Republic & $2 \%$ to $4 \%$ (since 2005$)$ & 1 year \\
\hline Mexico & $2 \%$ to $4 \%$ (since 2004$)$ & Medium term \\
\hline Norway & $1.5 \%$ to $3.5 \%$ (since 2001$)$ & Medium term \\
\hline Peru & $1.5 \%$ to $3.5 \%$ (since 2002$)$ & Medium term \\
\hline Philippines & $4 \%$ to $5 \%$ (for 2006$)$ & 1 year \\
\hline Poland & $1.5 \%$ to $3.5 \%$ (since 2004$)$ & Medium term \\
\hline Sweden & $1 \%$ to $3 \%$ (since 1995$)$ & Medium term \\
\hline United Kingdom & $2 \%$ (since 2004$)$ & Medium term \\
\hline
\end{tabular}

Source: various sources 
Having a target for the inflation rate is not enough. There are many different policies and instruments that will achieve an inflation target over the long run. Some policies will involve much larger fluctuations in other variables of concern to policy makers, such as the exchange rate or the real output. Thus, choosing an inflation target still leaves open most of the important questions about monetary policy decisions. That is where a monetary policy rule comes in. It provides the details about how the inflation target is to be met.

A good monetary policy rule is one in which the fluctuations of actual inflation around the inflation target rate are small. There can also be targets of other variables, as long as they are not inconsistent with the inflation target in the long run. For output, the target must be the natural rate of output. For the exchange rate, the target for appreciation or depreciation must be the difference between the domestic target inflation rate and the average inflation rate of other countries. Once such consistent long-run targets are set, then there is a variance trade-off between keeping small the fluctuations around the inflation target and the fluctuations around other targets [Taylor (1979)]. The variance trade-off replaces the old Phillips curve trade-off.

"But alas, inflation targeting does not guarantee that a central bank practising it will be able to deliver consistently low inflation. All the debates about how to formulate monetary policy in order to deliver the best outcomes are still relevant. Should we use monetary aggregates? Should we use Taylor rules? Should we simply adjust interest rates so that the direct 
price effects of the change in the exchange rate produce the desired effect on the domestic price level?” [D. Brash (1999), pp. 43 - 44]

There is no inconsistency between using inflation targeting as the objective and using a monetary aggregate as the instrument in the policy rule. In fact, because of the difficulties with the interest rate as an instrument in some transition economies, the money base may be a better instrument for achieving the inflation target. In earlier work on policy rule evaluation with an inflation target the money supply is the instrument [Taylor (1979)]. Inflation targeting is an alternative to fixed or managed exchange rates, not to policies that focus on the monetary aggregates.

Inflation forecast targeting means that the central bank chooses the instruments of policy so as to bring a forecast of inflation into equality with the inflation target at some future date. An example of inflation forecast targeting is the Monetary Policy Committee of the Bank of England, which describe their policy operations this way. Inflation forecast targeting, however, does not necessarily achieve well in obtaining an inflation target.

Inflation forecast targeting as defined here may be difficult in transition economies. The alternative to inflation targeting is simply to use a monetary policy rule. But inflation forecasts can be used in monetary policy rules in place of actual observed inflation values, such rules are called inflation forecast based policy rules [Batini and Haldane (1999); Rudebusch and Svensson (2000)]. 
In reality, any policy rule will involve some forecasts of inflation. The rule states policy should react to the current quarter, but data on the current quarter are not tabulated until after the quarter, so at least one-quarter forecasts are needed. Batini and Haldane (1999) showed that the optimal horizon - if one does not include output in the rule - is about three or four quarters.

Reifschneider and Williams (2000) have shown how the expectations effects of policy rules can greatly reduce the likelihood of getting into deep recessions. Such expectations effects are present in any monetary policy in which changes in the instruments depend on future events.

Woodford $(1999,2004)$ shows that these expectations effects indicate that the response of the interest variables has a lot of inertia. Inertia is created by slowly adjusting interest rate instruments to changes in the economy. The inertia actually increases the size of the response of variables that are forward looking such as long term bonds.

How should transition economies without highly liquid longer maturity markets view these results? They must not think that they can have a less clearly stated policy that will work better. Even if financial markets are not fully developed and there are few long term securities, movements in the exchange rate, the price of land, and even wages are affected by expectations of the future. It will be easier for the private sector to form expectations if the central bank is clear in its intentions through some kind of policy rule. 
However, without long term markets, it may be wise to react more quickly and by a larger amount because the shorter term interest rates will have to do more of the work. This suggests that "optimal" monetary policy rules in transition economies should be more responsive than optimal policy rules in more developed economies.

The exchange rate is part of the transmission mechanism in many of the models used for policy evaluation. The exchange rate enters both in the determination of net exports and in equations describing how the prices of foreign goods are passed through to domestic prices. And there is a link between the exchange rate and the interest rate through capital markets. It should be noted, however, that the models that have been used for policy evaluation assume perfect capital mobility.

The policy evaluation research that helped design the Taylor rule considered the role of the exchange rate. Simulations of multi-country models led to the belief that if the central bank reacted too strongly to the exchange rate, then inflation-output performance would deteriorate. However, the same conclusion would not necessarily be reached for small open transition economies. A country's size, openness, capital mobility, and degree of exchange market development would matter as well [Ball (1999); Svensson (1999); Batini, Harrison and Millard (2001)].

Evidence suggests that simple policy rules that focus on a smoothed inflation measure and real output and do not try to react too much to the exchange rate might actually work well in transition economies. However, the current models may understate the exchange 
rate effects in small open economies and therefore tend to underestimate the costs of exchange rate fluctuations which may be very high in transition economies where there is a mismatch of assets by currency or duration. The forward-looking nature of the exchange rate suggests that there may be significant gains from policies that utilize rational expectations in the same way that inertial rules for the interest rate do in closed economy models [Woodford (1999, 2004)].

\section{Political Risk and Ambiguity}

As opposed to ordinary risks, some of the risks faced by financial markets fail to be calculable. Such non-calculable risks are referred to as instances of ambiguity. This distinction between calculable risk in and non-calculable ambiguity was already made by Knight [Knight (1921)] and ambiguity, therefore, is sometimes referred to as Knightian uncertainty.

Regarding the impact of the amount of ambiguity - and its counterpart: the level of confidence - on interest rates Keynes (1937, p. 116) observes:

“... partly on reasonable grounds and partly on instinctive grounds, our desire to hold money as a store of wealth is a barometer of the degree of our distrust of our own calculations and conventions concerning the future. ... ... the quantity of hoards can [...] be altered [...] if the total quantity of current money income $[. .$.$] is changed; whereas fluctuations in the degree of$ 
confidence are capable of having quite a different effect, namely, in modifying [...] the amount of premium which has to be offered to induce people not to hoard.”

Political risk is a prominent form of ambiguity in the context of monetary policy and has a significant impact on investor confidence. Non-calculable political risk is much more prominent in transition economies than in the developed economies. Its presence leads to an ambiguity premium on the real interest rate. When investors are pessimistic, i.e. ambiguity averse, this premium is positive as in the case of the normal risk premium. In the case investors are optimistic, i.e. ambiguity loving, the ambiguity premium will be negative. Thus, the ambiguity premium supplements the usual risk premium [Spanjers (1999)].

The ambiguity premium is likely to be more volatile than the risk premium, as the level of non-calculable political risk is subject to rapid and violent fluctuations, even if the fundamentals of the economy remain unchanged. The added presence of the ambiguity premium makes the nominal interest rate even less suited as a policy instrument for transition economies than the discussion in Section 2 indicates.

The impact of ambiguity on the instruments of monetary policy is not restricted to the interest rate. The ambiguity premium incorporated in the exchange rate of transition economies is even more sensitive to unexpected political events and loss of confidence. As is argued in Spanjers (2005) two different types of loss of confidence - and therefore 
two different sources for changes in the ambiguity premium - can be identified. The first is an exogenous loss of confidence as can be observed after an unexpected political event, e.g. the fall of a government or the events in the wake of the "Orange Revolution" in the Ukraine. The second is an endogenous loss of confidence as it may be observed after a plausible political event occurs, the likelihood of which was at best vaguely known.

Keynes (1937, pp. 114 - 115) highlights that decisions which are made in the presence of ambiguity are vulnerable to sudden violent changes:

"Now a practical theory of the future [...] has certain marked characteristics. In particular, being based on so flimsy a foundation, it is subject to sudden and violent changes. The practice of calmness and immobility, of certainty and security, suddenly breaks down. New fears and hopes will, without warning, take charge of human conduct. The forces of disillusion may suddenly impose a new conventional basis of valuation. All these pretty, polite techniques, made for a well-panelled board room and a nicely regulated market, are liable to collapse. At all times vague panic fears and equally vague and unreasoned hopes are not really lulled, and lie but a little way below the surface.”

In our opinion, both ambiguity and sudden violent changes in investor behaviour are leading characteristics in many currency crises and in the 1997 East-Asian crisis in particular. Therefore, we take a closer look at Keynes' intuition regarding ambiguity and 
its consequences before discussing the potential impact of ambiguity on monetary policy rules.

Economists in his days, Keynes (1937, pp. 112 - 113) notes, were reluctant to consider uncertainty. If they considered uncertainty at all - be it in the form of expectations or otherwise - they only focus on calculable risk. The use of this approach of subjective expected utility and rational expectations, is, in Keynes' view, based on an inappropriate model of decision making. He considers this model particularly inappropriate when decisions regarding "wealth" and "wealth accumulation" are concerned. Such decisions are particularly prone to the impact of non-calculable risks and, therefore, cannot be adequately justified by the use of subjective expected utility.

From here, he proceeds to the next natural question: how are appropriately founded decisions made in an environment that displays a certain amount of non-calculable risk? His answer is that what decision makers do in the presence of ambiguity is to ignore it as good as they can, hoping that the current state of opinion in the market is a more or less fair summary of the future perspectives:

“[...] Nevertheless, the necessity for action and for decision compels us as practical men to do our best to overlook this awkward fact and to behave exactly as we should if we had behind us a good Benthamite calculation of a series of prospective advantages and disadvantages, each multiplied by the appropriate probability, waiting to be summed.” [Keynes (1937), p. 114] 
It is only when "something new and relevant comes into the picture" that the existing state of opinion is no longer accepted as a fair and useful summary of future perspectives:

"How do we manage in such circumstances to behave in a manner which saves our faces as rational, economic men? We have devised for the purpose a variety of techniques, of which much the most important are the three following:

(1) We assume that the present is a much more serviceable guide to the future than a candid examination of past experience would show it to have been hitherto. In other words we largely ignore the prospect of future changes about the actual character of which we know nothing.

(2) We assume that the existing state of opinion as expressed in prices and the character of existing output is based on a correct summing up of future prospects, so that we can accept it as such unless and until something new and relevant comes into the picture.

(3) Knowing that our own individual judgement is worthless, we endeavour to fall back on the judgement of the rest of the world which is perhaps better informed. That is, we endeavour to conform with the behaviour of the majority or the average. The psychology of a society of individuals each of whom is endeavouring to copy the others leads to what we may strictly term a conventional judgement.” [Keynes (1937), p. 114] ${ }^{4}$

\footnotetext{
${ }^{4}$ Italics added.
} 
In Keynes' view this leads to severe consequences of relatively small changes in what would be considered only marginally relevant areas. This applies when considering the ambiguity premium in interest rates or in the case of currency crises.

Next, Keynes shifts his focus on economic theory and economic theorists who, in his view (in 1937) were slow to duly recognize the relevance of ambiguity and to incorporate it in their thinking accordingly:

"Perhaps the reader feels that this general, philosophical disquisition on the behaviour of mankind is somewhat remote from the economic theory under discussion. But I think not. [...] I accuse the classical economic theory of being itself one of those pretty, polite techniques which tries to deal with the present by abstracting from the fact that we know very little about the future.

I daresay that a classical economist would readily admit this. But, even so, I think he has overlooked the precise nature of the difference which his abstraction makes between theory and practice, and the character of the fallacies into which he is likely to be led.” [Keynes (1937), p. 115]

Various kinds of adverse changes in the premium for ambiguity of assets in transition economies may cause currency crises, loss of confidence being the most prominent among them. Both the interest rate and the exchange rate are vulnerable to changes in non-calculable political risk, leading to increased volatility and to difficulties in 
measuring their equilibrium levels. This reinforces the conclusion in Section 3 above, that the optimal targets for transition economies may be inflation and output, with a monetary aggregate - e.g. the money base - as the optimal policy instrument.

\section{Monetary Policy and Ambiguity}

The above discussion of political risk and ambiguity raises the broader question how ambiguity affects the outcomes of monetary policy. Here the focus is on the effects of ambiguity regarding either the specific reactions triggered by the monetary policy or the predictability of central bank behaviour. Wagner (2005) observes that in the modern literature three different sources of uncertainty are analyzed:

1. Uncertainty regarding the current state of the economy, caused by the lags with which data become available. (Data uncertainty)

2. Uncertainty regarding the structure and the functioning of the economy. (Model uncertainty and parameter uncertainty)

3. Uncertainty regarding the interaction between the central bank and the public. (Strategic uncertainty)

The analysis of these forms of uncertainty typically takes place in Bayesian models, where the risks are perfectly calculable. If, however, the uncertainty is considered to have a significant non-calculable component, specific methods for modeling ambiguity are required. But even if model-builders are willing to include ambiguity in their models, they face a seemingly impossible task: how to make the non-calculable calculable? 
This problem was solved by Schmeidler (1982/89) and Gilboa (1987) who extended the axiomatic approach of the subjective expected utility theory. It is based on the assumption that decision makers, even if they face non-calculable risks, can still express a clear preference when facing two alternatives. That is, they can state either which alternative they prefer or that they are indifferent between the two. If such preferences satisfy certain properties similar to - but slightly weaker than - those of the subjective expected utility theory, then these preferences can be represented by the generalized expected utility of the outcomes that follow a non-additive probability measure as obtained by applying the Choquet integral. In situations in which no preferences as required in this approach are given, there is no obvious way to make the non-calculable calculable.

Therefore, in the setting where a central bank faces data uncertainty, model uncertainty or parameter uncertainty, more or less sophisticated versions of sensitivity analysis are the only options available. This is the approach which is effectively taken in the literature on robust control in monetary policy [Svensson (2000)]. Even if some of the formulations are similar to those of models that deal with ambiguity, the parallel is misleading. In the end, questions regarding the appropriate trade-off of the consequences of ambiguity against other relevant aspects cannot be solved within the model. The trade-off remains fully at the discretion of the policy maker. 
The situation is different when the public faces strategic uncertainty. Strategic uncertainty affects the functioning of the economy through the expectations of the decision makers, e.g. the central bank and the public. These expectations are formed much in line with Keynes' observations as cited above. In principle, it is possible to extract this information regarding the perceived amount of ambiguity and the prevailing attitudes towards it and to include them in the model. If now, for one reason or another, the amount of ambiguity and/or the attitudes towards it change, it would be possible to predict the effects on the monetary policy outcomes. As opposed to the literature on robust control, the latter strand of literature is still in its infancy [see Caglianrini and Heath (2000), Chprits and Schipper (2003) and Spanjers (2007)].

In Spanjers (2007) the interaction between a central bank and the public is analyzed in a standard setting where both the central bank and the public face ambiguity. The public faces ambiguity regarding the trustworthiness of the central bank, whereas the central bank faces ambiguity regarding the effectiveness of surprise inflation. When both the public and the central bank are pessimistic, it is found that under inflation targeting the equilibrium level of inflation is higher than it would have been in the absence of ambiguity.

Future research on monetary policy rules in transition countries, faces the challenging and interesting question which monetary policy rules are most suited when economies face specific kinds of ambiguity. How will the source of ambiguity influence the optimal 
monetary policy rule? How are the results affected when the ambiguity affects different decision makers: the central bank, the domestic public and foreign investors?

\section{Concluding Remarks}

The most certain thing in the world is uncertainty. In the presence of random shocks, liquidity crises and the loss of confidence or reputation, uncertainty matters. But how should it be modeled and understood? Should we use Bayesian methods for estimating Demand/Supply General Equilibrium Models? Should we use flexible priors or perhaps even modern methods for modeling ambiguity? For transition economies, a further question that arises is: how do we model the role of uncertainty and ambiguity in formulating expectations in the context of monetary policy rules? And regarding the issue of commitment in a timeless perspective: can we be confident that the time inconsistency problem can be solved in a satisfactory way?

At the moment, the trinity of a flexible exchange rate, an inflation target and a monetary policy rule still stands tall in transition economies and a modified Taylor rule could be an important pillar. It would seem a sensible idea to perform a welfare analysis using a linear quadratic approach to derive optimal monetary policy rules. Another idea would be to use a foreign currency premium to minimize risk. Or one could devise models to analyze the impact of foreign interest shocks. In each of these cases, though, a Bayesian method could be used for the estimation of uncertainty. 


\section{References}

Ball, R. (1999), The Institutional Foundations of Monetary Commitment: A Comparative Analysis, World Development, Vol. 27, pp. 1821-42.

Batini, N, R. Harrison and S. Millard (2001), Monetary Policy Rules for Open Economies, Working Paper 149, Bank of England.

Batini, N. and A. Haldane (1999), Forward-Looking Rules for Monetary Policy, in Monetary Policy Rules, Ed. J. Taylor, pp. 157 - 202, University of Chicago Press, Chicago.

Brash (1999), Inflation Targeting: An Alternative Way of Achieving Price Stability, Reserve Bank of New Zealand, Bulletin, Vol. 62, pp. 36 - 45.

Caglianrini, A. and A. Heath (2000), Monetary Policy Making in the Presence of Knightian Uncertainty, Mimeo, Economic Research Department, Reserve Bank of Australia, Sidney.

Chprits, E. and B. Schipper (2003), Knightian Intransparency of Central Bank and Labor Union, Mimeo, Department of Economics, University of Bonn, Bonn. 
Gilboa, I. (1987), Expected Utility with Purely Subjective Non-Additive Probabilities, Journal of Mathematical Economics, Vol. 18, pp. 65-88.

Keynes, J. (1937), The General Theory of Unemployment, from Quarterly Journal of Economics, Collected Writings, Vol. 14, pp. 109 -124, McMillan, London.

Knight, F. (1921), Risk, Uncertainty and Profit, Houghton Miffin, Boston.

McCallum, J. (1988), Is Increased Credibility Stabilizing?, Journal of Money, Credit and Banking, Vol. 20, pp 155-66.

Reifschneider, D. and J. Williams (2000) Three Lessons for Monetary Policy in a LowInflation Era, Journal of Money, Credit and Banking, Vol. 32, pp. 936-966.

Rudebusch, G. and L. Svensson (1999), Policy Rules and Inflation Trageting, in Monetary Policy Rules, Ed. J. Taylor, pp. 203-46, University of Chicago Press, Chicago

Schmeidler, D. (1982/89), Subjective Probability and Expected Utility Without Additivity, Econometrica, Vol. 57, pp. 571-587.

Spanjers, W. (1999), Liquiditätsversorgung bei Knight'scher Unsicherheit: Ein theoretischer Vergleich von Banken und Märkten (Provision of Liquidity under 
Knightian Uncertainty: A Theoretical Comparision of Banks and Markets), Habilitation Thesis, University of Saarland, Saarbrücken.

Spanjers, W. (2005), Loss of Confidence and Currency Crises, Discussion Paper 2005/2, School of Economics, Kingston University, Kingston-upon-Thames.

Spanjers, W. (2007), Central Banks and Ambiguity, [forthcoming], International Review of Economics and Finance.

Svensson, L. (2000), Robust Control Made Simple, Mimeo, Princeton University, Princeton.

Taylor, J. (1979), Staggered Wage Setting in a Macro Model, American Economic Review, Papers and Proceedings Vol. 69, pp. 108-13.

Taylor, J. (1993), Discretion versus Policy Rules in Practice, Carnegie-Rochester Conferences Series on Public Policy, Vol. 39, pp. 195-214.

Wagner, H. (2005) Unsicherheit in der Zentralbankpolitik (Uncertainty in Central Banking Policy), Mimeo, University of Hagen, Hagen.

Woodford, M. (1999), Optimal Monetary Policy Inertia, Manchester School, Vol. 67, pp. $1-35$. 
Woodford, M. (2004), Inflation Targeting and Optimal Monetary Policy, Federal Reserve Bank of St. Louis Review, Vol. 86, pp. 15-41. 